but occasionally the organism will spread to the lungs and cause a more serious chest infection. Carrying of organisms from an infected patient on the hands of the staff is probably one of the main routes by which infection spreads in these units, though its original source is often uncertain. Mechanical ventilators are not necessarily the main source of infection. ${ }^{7}$ Many possible human and inanimate sources of pseudomonas have been described, ${ }^{9}$ and sinks or drains are often suspected as the origin of infection because they are usually found to be contaminated. Though infection probably arising from a sink or drain has been reported, ${ }^{10} 11$ typing of pseudomonas strains suggests that they are an uncommon source. Another possible source is hospital food, and recent studies in one hospital suggest that patients commonly get food contaminated with Ps. aeruginosa. But the relevance of this observation to clinical infection is uncertain. ${ }^{12}$

Clinical pseudomonas infection has been increasing in recent years in young infants with debilitating illness, ${ }^{13}$ and colonization of the nose, throat, and faeces with Ps. aeruginosa tends to occur particularly in ill, male premature babies. ${ }^{14}$ In infant nurseries pseudomonas strains are not often acquired from mothers but mainly from environmental sources-for example, incubators, ${ }^{15}$ contaminated breast pumps, ${ }^{16}$ infant feeds, ${ }^{17}$ hexachlorophane, ${ }^{18}$ and other detergent preparations ${ }^{19}$ - and are likely to be transferred on the hands of nurses. In a recently reported study A. J. Barson described 40 cases of fatal pseudomonas bronchopneumonia in a retrospective survey of 600 consecutive necropsies at the Children's Hospital, Toronto. ${ }^{20}$ The incidence of pseudomonas deaths increased from 6 cases in 1965-6 to 40 in 1967 and 8 months of 1968 . Of the 40 patients of pseudomonas bronchopneumonia, over three-quarters had been intubated with endotracheal tubes and two-thirds showed laryngeal or tracheal ulceration. The average birth-weight of those patients who were newborn babies was lower than in the generality of newborn babies that came to necropsy. Infection was in all cases complicated by a primary disease, of which the respiratory distress syndrome was the most common $(40 \%)$. The author considers that the use of humidified ventilating equipment was an important predisposing factor.

The efficient disinfection of ventilating equipment has been a subject of considerable discussion and research over the past few years. Disinfection of nebulizers with $0.25 \%$ acetic acid appeared to reduce the incidence of necrotizing pneumonia in one study, ${ }^{21}$ though other workers have found that chemical methods were unreliable. ${ }^{22}$ Disinfection by heat is always preferable to chemical methods, and manufacturers should be encouraged to design equipment which can be easily dismantled, cleaned, and autoclaved. Respiratory ventilators with expiratory and inspiratory circuits are particularly difficult to clean and disinfect. Though many methods are available, and most appear to be reasonably effective, ${ }^{23} 24$ none is entirely satisfactory. Meanwhile, the incorporation of moisture traps in the expiratory and inspiratory circuits, daily changing of tubing and traps, and disinfection of the machine between patients should considerably reduce the risk of infection. The treatment of equipment such as ventilators, suction apparatus, and incubators in a central area of the hospital should improve standards of maintenance and disinfection. The infection of burned patients by pseudomonas strains has been considerably reduced by the use of whole-body plastic isolators, ${ }^{25}$ and a similar technique could be modified for nursing other types of patient, including premature infants, who are particularly liable to acquire pseudomonas infection.
1 Phillips, I., and Spencer, G., Lancet, 1965, 2, 1325.

2 Bassett, D. C. J., Thompson, S. A. S., and Page, B., Lancet, 1965, 1, 781. 3 Cartwright, R. Y., and Hargrave, P. R., Lancet, 1970, 1, 40.

Beck, A., and Zadeh, J. A., Lancet, 1968, 1, 533.

Reinarz, J. A., Pierce, A. K., Mays, B. B., and Sanford, J. P., fournal of Clinical Investigation, 1965, 44, 831.

- Sanders, C. V., Luby, J. P., Johanson, W. G., Barnett, J. A., and Sanford, J. P., Annals of Internal Medicine, 1970, 73, 15.

Lowbury, E. J. L., Thom, B. T., Lilly, H. A., Babb, J. R., and Whittall. K., fournal of Medical Microbiology, 1970, 3, 39.

${ }^{8}$ Favero, M. S., Bond, W. W., Peterson, N. J., and Carsen, L. A., Bacteriological Proceedings, 1970 , p. 11.

10 British Medical fournal, 1967, 4, 309.

${ }^{10}$ Kohn, J., British Medical fournal, 1967, 4, 548.
11 Fierer, J., Taylor, P. M., and Gezon, H. M., New England fournal of Medicine, 1967, 276, 991 .

12 Shooter, R. A., et al., Lancet, 1969, 1, 1227.

${ }^{13}$ Asay, L. D., and Koch, R., New England Fournal of Medicine, 1960, 262,

1062.
14 Davies, P. A., Darrell, J. H., Chandran, K. R., and Waterworth, P. M., in The Control of Chemotherapy, ed. P. J. Watt, p. 49. Edinburgh, Livingstone, 1970

${ }_{15}$ Barrie, D., Archives of Disease in Childhood, 1965, 40, 555.

16 Thom, A. R., Cole, A. P., and Watrasiewicz, K., Lancet, 1970, 1, 560.

17 Ayliffe, G. A. J., Collins, B. J., and Pettit, F., Lancet, 1970, 1, 559.

${ }_{18}$ Ayliffe, G. A. J., Barrowcliff, D. F., and Lowbury, E. J. L., British Medical fournal, 1969, 1, 505 .

${ }^{19}$ Cooke, E. M., Shooter, R. A., O'Farrell, S. M., and Martin, D., Lancet, 1970, 2, 1045.

${ }^{20}$ Barson, A. J., Archives of Disease in Childhood, 1971, 46, 55.

${ }^{21}$ Pierce, A. K., Sanford, J. P., Thomas, G. D., and Leonard, J. S., New England Fournal of Medicine, 1970, 282, 528.

22 Grieble, H. G., Colton, F. R., Bird, T. J., Toigo, A., and Griffith, L. G., New England fournal of Medicine, 1970, 282, 531.

${ }_{23}$ Judd, P. A., Tomlin, P. J., Whitby, J. L., Inglis, T. C. M., and Robinson, J. S., Lancet, 1968, 2, 1019. ${ }^{24}$ Eykyn, S., British Hospital Fournal and Social Service Review, 1970, 80,

${ }^{25}$ Lowbury, E. J. L., in Aerobiology: Proceedings of Third International Symposium, ed. I. H. Silver, p. 131. New York, Academic Press, 1970.

\section{Epiglottitis in Adults}

It is generally assumed that acute epiglottitis is an illness of children under the age of 5 . That it occurs in adults, though possibly less commonly, is not yet fully appreciated. A recent article ${ }^{1}$ describing two cases in adults re-emphasizes the seriousness of the condition and the high mortality. The author of the article, in common with others, ${ }^{2-4}$ describes the apparent mildness of the condition at the onset, and the rapidity with which respiratory obstruction supervenes.

The disease often starts as an infection of the upper respiratory tract and progresses rapidly, with increasingly severe sore throat, dysnhagia, cough, and voice change. Pyrexia, about $100^{\circ}-102^{\circ} \mathrm{F}\left(37 \cdot 8^{\circ}-38 \cdot 9^{\circ} \mathrm{C}\right)$, is a constant feature, and the rapid onset of restlessness, prostration, and dyspnoea from laryngeal obstruction are typical of the disease. Laryngeal stridor and dyspnoea may come on as quickly as four to six hours after the onset of the illness.

There may be little to see in the oropharynx apart from redness of the mucosa, oedema of the uvula, and viscid secretions. Indirect laryngoscopy in adults, or simply depressing the tongue in young children will reveal a swollen, red epiglottis curled backwards and downwards on itself in the shape of a horseshoe. ${ }^{3}$ Inspiratory stridor and retraction of supraclavicular soft tissue indicate narrowing of the airway, and palpation of the neck may disclose diffuse swelling of soft tissue. 4

The organism recovered from the throat or epiglottis is usually Haemophilus influenzae type B, and blood culture is frequently positive for this organism, which is in keeping with the fulminating nature of the condition. The histological findings at necropsy are massive oedema of the epiglottis with infiltration by polymorphonuclear leucocytes, amounting in places to micro-abscess formation. Curiously, the tissues at the glottic level are nearly always spared.

Early antibiotic treatment is required if laryngeal obstruc- 
tion is to be prevented, the natural choice being ampicillin. It may be wise to supplement this with cloxacillin in case the condition is caused by a penicillinase-producing staphylococcus, but in patients who are allergic to penicillin the combination of chloramphenicol and lincomycin has been suggested. ${ }^{2}$

The point needs stressing that acute epiglottitis, uncommon though it is, occurs in adults as well as young children, and though it may start innocuously it is a rapidly progressive illness, with a high mortality from laryngeal obstruction and toxaemia. The diagnosis should be considered in an adult who presents with acute sore throat and minimal pharyngeal signs, but who has dysphagia, respiratory disstress, and some voice change. The need for early tracheostomy, once symptoms of laryngeal obstruction have appeared, should be considered.

1 Rainer, E. H., Fournal of Laryngology and Otology, 1971, 85, 493

2 Gorfinkel, J. H., Brown, R., and Kabins, S. A., Annals of Internal Medicine, $1969,70,289$

${ }^{3}$ Vetto, R. R., Fournal of the American Medical Association, 1960, 173, 990

- Johnstone, J. M., and Lawy, H. S., Lancet, 1967, 2, 134.

\section{Rickets in the Premature Baby}

It is unwise to add medicine to an infant's feed, because he may leave some of the feed and therefore receive an inadequate dose of the medicine. Now a group of doctors ${ }^{1}$ at the Sick Children's Hospital, Toronto, have shown that it is unwise to rely on vitamin-D-fortified milk to prevent rickets in premature and other infants of low birth weight, because the infants may leave some of the feed or otherwise take too little milk, so that the intake of the vitamin is inadequate. It had been the hospital custom to give vitamin D, 400 units per day, in addition to the milk formula, which contained 450 units of vitamin $D$ per litre. In a sixmonth period four infants (weighing $680 \mathrm{~g}, 870 \mathrm{~g}, 935 \mathrm{~g}$, and $1,300 \mathrm{~g}$ respectively, three of them small for dates) developed rickets. It was then found that as a result of the small feeds which they were taking they were receiving approximately $50 \mathrm{IU}$ of vitamin $\mathrm{D}$ per day for the first month, and that only when they reached $2,500 \mathrm{~g}$ in weight did they take enough to obtain 300 IU per day.

It was noted that in the U.S.A. and Canada most fluid and evaporated milk contained approximately 450 IU of vitamin D per litre of reconstituted milk. In Great Britain the prophylactic and therapeutic doses of vitamin $\mathrm{D}$ are not accurately known, but it is commonly thought that 150 300 IU of the vitamin per day is probably adequate for prophylaxis and 300 to 500 IU for treatment. Unfortunately the question of the correct dosage is not simple. Paediatricians are afraid of overdosage, with resultant hypercalcaemia, and a quantity of vitamin D safe for one child may be toxic for another. M. Seelig ${ }^{2}$ has suggested that American children may be receiving too much vitamin D for safety. Thirty-six years ago J. M. Lewis ${ }^{3}{ }^{4}$ showed that 90 units of crystalline vitamin D in milk was more effective in the treatment of rickets than 900 units in oil; and that 10 to 15 drops of vitamin $D$ in oil were necessary to cure rickets, while only one drop was necessary if it was incorporated in milk. Others subsequently made similar observations. Hence it would seem that the prophylactic dose of vitamin $\mathrm{D}$ in oil may be different from that in fortified milk.

We have to strike a balance between risking the development of hypercalcaemia on the one hand and rickets on the other. Many doctors believe it is probably unnecessary and possibly unwise to give additional vitamin $\mathrm{D}$ to full-term babies fed on evaporated or dried milk or cereals -all of them in Britain fortified with vitamin D. But the work of P. K. Lewin and colleagues in Toronto ${ }^{1}$ indicates that the daily intake of vitamin $\mathrm{D}$ by small babies of low birth weight may be inadequate because of the low quantities of fortified milk which they are able to take.

\footnotetext{
${ }^{1}$ Lewin, P. K., Reid, M., Reilly, B. J., Swyer, P. R., and Fraser, D., fourna of Pediatrics, 1971, 78, 207.

Seelig, M., Clinical Pediatrics, 1970, 9, 380.

3 Lewis, J. M., Fournal of Pediatrics, 1935, 6, 362

4 Lewis, J. M., Fournal of Pediatrics, 1936, 8, 308
}

\section{Reflux and Hernia}

An exciting and provocative hypothesis about the antireflux mechanism of the stomach has recently been published and will cause consternation among the traditionalists, though it may not change the form of practical methods of treating the symptoms and complications of reflux for some time to come.

S. Cohen and L. D. Harris ${ }^{1}$ found that when intraabdominal pressure was increased the pressure within the lower oesophageal sphincter also increased. Increase in pressure in the lower oesophageal sphincter always exceeded the increase in intra-abdominal pressure (measured as intragastric) in a group of patients without symptoms of reflux, whether they had a hiatus hernia or not. On the other hand, increase in pressure in the lower oesophageal sphincter was always less than the increase in gastric pressure in another group of patients who had symptoms of reflux, again regardless of whether they had a hiatus hernia or not. The resting or baseline pressure in the sphincter of all the patients with symptoms of reflux was less than the pressure in those without symptoms.

The authors draw several conclusions: firstly, that the common sliding hiatus hernia does not by itself make the sphincter weaker; secondly, the pressure surrounding the sphincter does not affect its strength; thirdly, the sphincter becomes stronger as intragastric pressure increases, perhaps by a reflex process; and fourthly, the ability to become stronger is not affected by the sphincter's location above or below the diaphragm. We may also conclude that the ability to become stronger is related in some way to the resting pressure in the sphincter and not to the increase in intra-abdominal pressure. The weaker the sphincter initially, the less the increase in pressure as intragastric pressure rises, until intragastric pressure equals or exceeds sphincteric pressure and reflux occurs. The fault seems to lie within the sphincter. If it contracts well in the resting state, it will always overcome intragastric pressure by contracting even harder when challenged. If it is inherently weak, its response will be correspondingly inadequate. S. J. Rosenberg and Harris ${ }^{2}$ suggest that incompetence of the lower oesophageal sphincter is not a primary defect of the muscle but is related to decreased stimulation by endogenous gastrin. They compared the dose response curves to pentagastrin of the lower oesopha- 